\title{
Changes in Eating Habits and Lifestyles in a Peruvian Population during Social Isolation for the COVID-19 Pandemic
}

\author{
Salomón Huancahuire-Vega $\mathbb{D}^{1},{ }^{1}$ Edda E. Newball-Noriega, ${ }^{1}$ Ricardo Rojas-Humpire $\mathbb{D}{ }^{1}$ \\ Jacksaint Saintila $\mathbb{D}^{2}{ }^{2}$ Mery Rodriguez-Vásquez, ${ }^{2}$ Percy. G. Ruiz-Mamani, ${ }^{3}$ \\ Wilter C. Morales-García, ${ }^{4}$ and Michael White ${ }^{5}$ \\ ${ }^{1}$ Grupo de Investigación P53, Escuela de Medicina Humana, Facultad de Ciencias de la Salud, Universidad Peruana Unión, \\ Lima, Peru \\ ${ }^{2}$ Departamento de Nutrición, Escuela de Nutrición Humana, Facultad de Ciencias de la Salud, Universidad Peruana Unión, \\ Lima, Peru \\ ${ }^{3}$ Escuela Profesional de Enfermería, Facultad de Ciencias de la Salud, Universidad Privada San Juan Bautista, Lima, Peru \\ ${ }^{4}$ Escuela de Posgrado, Universidad Peruana Unión, Lima, Peru \\ ${ }^{5}$ Dirección General de Investigación, Universidad Peruana Unión, Lima, Peru
}

Correspondence should be addressed to Salomón Huancahuire-Vega; salomonhuancahuire@upeu.edu.pe

Received 4 August 2021; Revised 15 October 2021; Accepted 18 November 2021; Published 1 December 2021

Academic Editor: Toshikazu Suzuki

Copyright (c) 2021 Salomón Huancahuire-Vega et al. This is an open access article distributed under the Creative Commons Attribution License, which permits unrestricted use, distribution, and reproduction in any medium, provided the original work is properly cited.

\begin{abstract}
Background. Peru has one of the highest infection and death rates in the world for the COVID-19 pandemic. The government implemented house confinement measures with probable consequences on lifestyle, particularly affecting eating habits, physical activity, sleep quality, and mental health. Objectives. The aim of this study was to assess the lifestyles, physical activity, and sleep characteristics, as well as changes in eating habits in a Peruvian population during the first wave of the COVID-19 pandemic. Methods. A cross-sectional descriptive study was performed. We analyzed Peruvian adults based on an online self-administered questionnaire divided into sociodemographic, anthropometrics, COVID-19 diagnosis reported, lifestyle habits, and frequency of consumption of foods. Results. During confinement for COVID-19, 1176 participants were studied. Of these, most reported weight gain (1 to $3 \mathrm{~kg}$ ) and $35.7 \%$ were overweight. The lifestyles habits showed that $54.8 \%$ reported doing physical activity and $37.2 \%$ sleep less. The Peruvian sample presented a main meal pattern of breakfast (95.7\%), lunch (97.5\%), and dinner (89.1\%). Likewise, eating habits before and during COVID-19 pandemic showed that vegetables (OR:1.56, CI95\% 1.21-200), fruit (OR: 1.42, CI95\% 1.10-1.81), legumes (OR:1.67, CI95\% 1.23-2.28), and eggs (OR: 2.00, CI95\% 1.52-2.65) presented significant consumption increase during social isolation, while bakery products (OR: 0.74, CI95\% 0.56-0.97), meat, snack, refreshment, and fast food decreased in consumption. Other foods showed no significant differences. Conclusion. This study showed an important frequency of overweight and sleep changes. There was a slight increase in physical activity despite the social isolation measures and an increase in healthy eating habits; nevertheless, the majority reported gaining weight.
\end{abstract}

\section{Introduction}

An announcement made by the WHO on January 30, 2020, declared COVID-19 a global health emergency due to the exponential growth of cases in China and other countries of the world [1]. As of July 23, 2021, according to the Coronavirus Resources Center at Johns Hopkins University, more than 192.7 million cases have been confirmed, while the number of deaths has risen to more than 4.139 million [2]. Given the circumstances and the measures needed to control the spread of the disease, government authorities were forced to take decisive actions, such as social distancing and mandatory isolation in homes, which have led to restrictions on various daily activities, with probable 
consequences on lifestyle, particularly affecting eating habits, physical activity, sleep quality, and mental health [3].

Peru is among the countries with the highest global contagion and mortality rates from COVID-19, which has led to estimating that life expectancy in this country has decreased during 2020 by more than two years [4]. In this country, the first case of COVID-19 infection was reported by the government on March 6, 2020. Since then, the government has implemented a series of preventive measures in order to limit and contain the spread of the disease. On March 16, the Peruvian government, through Supreme Decree No. 008-2020-SA, declared a nationwide state of health emergency for a period of ninety (90) calendar days, dictating prevention measures and mandatory social isolation (national quarantine) for the control of COVID-19 [5]. Subsequently, the government announced an extension that modified the restriction to a targeted social isolation, but the state of health emergency and social distancing measures were extended repeatedly and currently are set until September 31, 2021 [6].

The period of social isolation due to COVID-19 has caused a series of changes in people's daily routine and lifestyle [7]. Available evidence has shown that during the pandemic, physical activity decreased in the population, while the amount of screen time increased significantly [7]. In fact, prior to the pandemic, these factors, along with obesity, were described as a public health problem in the Peruvian population, and COVID-19 may make this situation even worse [8]. In addition, studies have shown the negative impact of sedentary behaviors on physical and mental health [9]. Likewise, the fear caused by COVID-19 has an indirect effect, causing negative emotions and affecting the quality of sleep, contributing to an increase in obesity [10].

Previous studies have demonstrated the beneficial effects of physical activity and sleep quality on mental health [11]. In addition, adequate physical activity can improve the quality of sleep, reducing the risk of morbidity from chronic noncommunicable diseases [12]. Furthermore, appropriate eating habits can be a protective factor for physical and mental health, disease prevention, and strengthening of the immune system [13]. Indeed, improved lifestyle, as a possible strategy that includes regular physical activity, less screen time, adequate rest, and proper dietary habits through a diet based on consumption of minimally processed plant foods and healthy fats, would lead to better control of chronic noncommunicable diseases and thus strengthen the immune system during the COVID-19 pandemic [13].

Additionally, evidence has shown that the risks of choosing inappropriate eating behaviors can increase as a psychological and emotional response to COVID-19 [14]. In fact, it has already been shown that negative emotional experiences can lead to overeating [15]. Eating habits characterized by a high consumption of ultra-processed, high-calorie-density foods and low intake of fiber, antioxidants, and other bioactive elements can affect the immune system, causing chronic activation of the innate system and inhibition of the adaptive immune system response by increasing oxidative stress, thus delaying defensive intervention against pathogens [16].
Many studies have evaluated dietary changes during the COVID-19 pandemic in different age groups and countries $[3,17,18]$, but, thus far, there is no study among adults from a Peruvian population. The objective of the present study was to evaluate the lifestyles, physical activity levels, and sleep characteristics, as well as changes in eating habits, in a Peruvian population during the period of social isolation due to the first wave of the COVID-19 pandemic.

\section{Materials and Methods}

2.1. Design and Participants. This is a cross-sectional descriptive study based on a self-administered questionnaire. This questionnaire was addressed to the Peruvian adult population (over 18 years of age) and was applied using nonprobabilistic convenience sampling. We included participants between 18 and 79 years old of both sexes from the different regions of Peru. Responses from 1218 participants were obtained, of which 42 were excluded because they did not completely fill out the questionnaire or did not sign informed consent, or certain inconsistencies related to age, height, weight, and so on cast suspicion on their accuracy.

The study followed the international ethical recommendations contained in The Declaration of Helsinki. All participants were informed about the characteristics of the study, as well as their anonymous, voluntary, and confidential participation. This study was approved by the Ethics in Research Committee of the Universidad Peruana Unión (No. 2020-CEUPeU-00013).

2.2. Procedure. The questionnaire was applied from July 16 to August 31, 2020 (while the Peruvian population was in partial confinement), using the Google Forms platform and disseminated through social networks (Facebook and WhatsApp) and institutional mailing lists. The questionnaire was completed through any electronic device with an Internet connection. On the initial page, the participants were explained the voluntary nature of their participation with informed consent, as well as the justification, objectives, possible risks, and benefits of the study before continuing with the instrument itself.

2.3. Questionnaire and Variables. The questionnaire was developed by the authors to specifically address the particularities of the current pandemic context and its impact on lifestyle. The questionnaire included 42 questions divided into four sections: sociodemographic data (10 questions: gender, marital status, age, level of education, occupational status, employment status, if the social isolation mandate was adhered to, duration of social isolation, and people in the home before and during social isolation), anthropometric data and COVID-19 diagnosis reported (5 questions: weight, height, weight change during social isolation, number of kilograms, and COVID-19 diagnosis), information on lifestyle habits (11 questions: physical activity, change and hours of sleep, and meals eaten per day during confinement), information on the frequency of consumption of the main food groups (16 questions: vegetables, fruit, 
TABLE 1: Sociodemographic and anthropometric data.

\begin{tabular}{|c|c|c|c|c|}
\hline Variables & Total $(n=1176)$ & Men $(n=571)$ & Women $(n=605)$ & $p$ value \\
\hline \multicolumn{5}{|l|}{ Age } \\
\hline $18-25$ yrs & $522(44.4)$ & $197(34.5)$ & $325(53.7)$ & \multirow[t]{4}{*}{$<0.001^{*}$} \\
\hline $26-40$ yrs & $396(33.7)$ & $213(37.3)$ & $183(30.2)$ & \\
\hline $41-55$ yrs & $200(17.0)$ & $115(20.1)$ & $85(14.0)$ & \\
\hline $56-70$ yrs & $58(4.9)$ & $46(8.1)$ & $12(2.0)$ & \\
\hline \multicolumn{5}{|l|}{ Marital status } \\
\hline Single & $796(67.7)$ & $339(59.4)$ & $457(75.5)$ & \multirow[t]{4}{*}{$<0.001^{*}$} \\
\hline Married & $333(28.3)$ & $205(35.9)$ & $128(21.2)$ & \\
\hline Separated or divorced & $42(3.6)$ & $25(4.4)$ & $17(2.8)$ & \\
\hline Widow(er) & $5(0.4)$ & $2(0.4)$ & $3(0.5)$ & \\
\hline \multicolumn{5}{|l|}{ Level of education } \\
\hline Primary incomplete & $4(0.3)$ & $4(0.7)$ & $0(0.0)$ & \multirow[t]{6}{*}{$0.004^{*}$} \\
\hline Primary completed & $9(0.8)$ & $4(0.7)$ & $5(0.8)$ & \\
\hline Secondary completed & $342(29.1)$ & $143(25.0)$ & $199(32.9)$ & \\
\hline Preparatory or tertiary completed & $199(16.9)$ & $89(15.6)$ & $110(18.2)$ & \\
\hline University degree completed & $447(38.0)$ & $237(41.5)$ & $210(34.7)$ & \\
\hline Graduate degree completed & $175(14.9)$ & $94(16.5)$ & $81(13.4)$ & \\
\hline \multicolumn{5}{|l|}{ Occupational status } \\
\hline Student & $459(39.0)$ & $159(27.8)$ & $300(49.6)$ & \multirow[t]{6}{*}{$<0.001^{*}$} \\
\hline Worker & $441(37.5)$ & $272(47.6)$ & $169(27.9)$ & \\
\hline Worker and student & $194(16.5)$ & $110(19.3)$ & $84(13.9)$ & \\
\hline Housewife & $19(1.6)$ & $1(0.2)$ & $18(3.0)$ & \\
\hline Unemployed & $58(4.9)$ & $25(4.4)$ & $33(5.5)$ & \\
\hline Retired & $5(0.4)$ & $4(0.7)$ & $1(0.2)$ & \\
\hline \multicolumn{5}{|l|}{ Employment status } \\
\hline I am not working & $541(46.0)$ & $189(33.1)$ & $352(58.2)$ & \multirow[t]{4}{*}{$<0.001^{*}$} \\
\hline Formal job with a contract & $362(30.8)$ & $201(35.2)$ & $161(26.6)$ & \\
\hline Self-employed & $159(13.5)$ & $114(20.0)$ & $45(7.4)$ & \\
\hline Public sector & $114(9.7)$ & $67(11.7)$ & $47(7.8)$ & \\
\hline \multicolumn{5}{|l|}{ Days under social isolation } \\
\hline Have not socially isolated & $143(12.2)$ & $68(11.9)$ & $75(12.4)$ & \multirow[t]{6}{*}{$0.019^{*}$} \\
\hline Less than 15 days & $37(3.1)$ & $16(2.8)$ & $21(3.5)$ & \\
\hline 15 to 30 days & $59(5.0)$ & $36(6.3)$ & $23(3.8)$ & \\
\hline 31 to 45 days & $41(3.5)$ & $25(4.4)$ & $16(2.6)$ & \\
\hline 45 to 60 days & $101(8.6)$ & $60(10.5)$ & $41(6.8)$ & \\
\hline More than 61 days & $795(67.6)$ & $366(64.1)$ & $429(70.9)$ & \\
\hline \multicolumn{5}{|l|}{ Body Mass Index (BMI) } \\
\hline Malnourished & $18(1.5)$ & $5(0.9)$ & $13(2.1)$ & \multirow[t]{5}{*}{$<0.001^{*}$} \\
\hline Normal & $639(54.3)$ & $245(42.9)$ & $394(65.1)$ & \\
\hline Overweight & $420(35.7)$ & $258(45.2)$ & $162(26.8)$ & \\
\hline Obesity I & $84(7.1)$ & $52(9.1)$ & $32(5.3)$ & \\
\hline Obesity II & $15(1.3)$ & $11(1.9)$ & $4(0.7)$ & \\
\hline \multicolumn{5}{|c|}{ Weight change during social isolation (gained) } \\
\hline $1-3 \mathrm{~kg}$ & $245(20.8)$ & $105(18.4)$ & $140(23.1)$ & \multirow[t]{6}{*}{$0.001^{*}$} \\
\hline $4-7 \mathrm{~kg}$ & $161(13.7)$ & $87(15.2)$ & $74(12.2)$ & \\
\hline $8-11 \mathrm{~kg}$ & $41(3.5)$ & $28(4.9)$ & $13(2.1)$ & \\
\hline$>12 \mathrm{~kg}$ & $14(1.2)$ & $6(1.1)$ & $8(1.3)$ & \\
\hline Yes, but unsure how much & $185(15.7)$ & $72(12.6)$ & $113(18.7)$ & \\
\hline No & $530(45.1)$ & $273(47.8)$ & $257(42.5)$ & \\
\hline \multicolumn{5}{|l|}{ COVID-19 diagnosis confirmed } \\
\hline No & $1074(91.3)$ & $521(91.2)$ & $553(91.4)$ & 1 \\
\hline Yes & $102(8.7)$ & $50(8.8)$ & $52(8.6)$ & \\
\hline
\end{tabular}

Data expressed as absolute and relative frequency (\%). COVID-19, coronavirus disease; yrs, years. ${ }^{*}$ Statistically significant, $p<0.05$.

legumes, dried fruit/nuts, meat, fish, eggs, milk, yogurt, bakery products, snacks, beverages, beer, wine, other alcohol, and fast food) before and during social isolation, based on five response categories: participants who reported having consumed food from 1 to 4 times/week were considered as low consumption, while high consumption was considered when they reported having consumed from 5 times/week to 2 or more times/day [19]. 
2.4. Statistical Analysis. The data analysis was performed in RStudio v4.0.2 (R Foundation for Statistical Computing, Vienna, Austria; http://www.R-project.org). The variables were encoded and analyzed as categorical. To descriptive analysis, categorical variables were clustered into tables with absolute and relative frequency (\%). For the comparative analysis, $\chi^{2}$ or Fisher's exact test was used for categorical variables depending on distribution of each variable. Subsequently, to determinate differences before and during the COVID-19 pandemic, the McNemar test was performed. Moreover, logistic regression models were performed to analyze the factors that influenced the odds of BMI and sleep changes. The results of logistic regression analyses were expressed as crude odds ratio (cOR), adjusted odds ratio (aOR) by sex and age, and 95\% confidence intervals $(95 \%$ CI). For all analyses, $p<0.05$ was considered statistically significant.

\section{Results}

A summary of the sample's sociodemographic characteristics can be found in Table 1. In total, 1176 participants were studied, 571 men and 605 women. The largest age groups were 18 to 25 years old $(44.4 \%)$ with predominant women and 26 to 40 years old $(33.7 \%)$ with predominant men. Overall, $67.7 \%$ were single and $38 \%$ had completed university studies. During social isolation, $39 \%$ of those sampled were students, $37.5 \%$ were workers, $30.8 \%$ worked with a formal contract, $46 \%$ were not working, and $67.6 \%$ were under social isolation for more than 61 days as of the date of the study.

A total of $35.7 \%$ of those studied were overweight and $8.4 \%$ were obese, with a majority of men in both groups. A large portion reported having gained weight, $20.8 \%$ and $13.7 \%$ between 1 to $3 \mathrm{~kg}$ and 4 to $7 \mathrm{~kg}$, respectively. Of all respondents, $8.7 \%$ had a confirmed diagnosis of COVID-19.

Some aspects of lifestyles showed patterns and changes when grouped by sex during the social isolation (Table 2). More than half of those studied affirmed to doing physical activity (54.8\%) between 1 and $2(14.7 \%)$ and 3 to $4(26.4 \%)$ days per week, for at least $30 \mathrm{~min}$. The reported sleep routine presented significate changes, wherein $37.2 \%$ responded that they slept less and $36.9 \%$ slept more hours at night compared to before the pandemic. The hours of sleep per night were largely between 4 and $6(35.6 \%)$ and 7 to $9(55.4 \%)$ hours.

Eating patterns during the social isolation showed that approximately 90 to $95 \%$ ate breakfast, lunch, and dinner. Additionally, some extra food consumption was reported for brunch ( 42.9 to $46.8 \%$ ), afternoon meal (38.2 to $39.8 \%$ ), and snacks ( 35.2 to $40.8 \%$ ); these results presented no differences by sex (Figure 1).

The eating habits showed some changes before and during social isolation (Table 3 ). Fruit and vegetables presented elevated frequency of consumption, while legumes and dried fruit/nuts showed low frequency of consumption (Figure 2). On the other hand, just vegetables (OR:1.56, CI95\% 1.21-200), fruit (OR: 1.42, CI95\% 1.10-1.81), and legumes (OR:1.67, CI95\% 1.23-2.28) presented significant consumption increase during social isolation.
Approximately, a quarter of the population presented high consumption of meat and eggs (Figure 3), while dairy products and fish showed low frequency of consumption. Among the animal-based foods, only eggs (OR: 2.00, CI95\% 1.52-2.65) presented significant consumption increase during social isolation. The consumption of alcoholic drinks and ultra-processed food was the lowest, while approximately $20 \%$ and $40 \%$ of sample presented high consumption of beverages and bakery products, respectively (Figure 4). In the processed food, just bakery products (OR: 0.74, CI95\% 0.56-0.97) presented change before and during social isolation.

Additionally, to determine factors associated with BMI and sleep changes, a multivariate regression analysis was made. Some factors showed association with BMI in the study sample during the COVID-19 pandemic (Table 4). In this sense, women (cOR:0.38, CI95\%: 0.30-0.48), vegetable consumption (cOR:0.77, CI95\%: 0.61-0.97), physical activity (PA) at home (cOR:0.55, CI95\%: 0.44-0.70), PA per week (cOR:0.89, CI95\%: 0.89-0.94), and time of PA decreased the probability of high BMI in bivariate analysis. In the adjusted analysis, PA at home (aOR:0.58, CI95\%: 0.45-0.74) reduced the probability of high BMI by $42 \%$, PA of less than $30 \mathrm{~min}$ until 1 hour reduced the probability of high BMI by $39 \%$ and $46 \%$, respectively, and the addition of each day of PA reduced the probability of high BMI by $11 \%$. Furthermore, the addition of each additional year of age increases the probability of high BMI by $5 \%$.

The sleep changes (sleep more or less) presented an association with some variables during the COVID-19 pandemic (Table 5). In this sense, women (cOR:1.52, CI95\%: $1.17-1.98$ ), social isolation more than 61 days (cOR:2.30, CI95\%: 1.57-3.35), and meals per day (cOR:1.21, CI95\%: 1.08-1.35) showed an increase of sleep changes in bivariate analysis. In the adjusted analysis, the social isolation for more than 61 days increased the probability of sleep changes by 2.31 times (aOR:2.31, CI95\%: 1.57-3.38), while the addition of each additional meal in the day increased the probability of sleep changes by $17 \%$ (aOR: 1.17, CI95\%: 1.05-1.32). Additionally, the addition of each year of age decreased the probability of sleep changes in this population by $2 \%$.

\section{Discussion}

During social isolation due to the first wave of the COVID19 pandemic, most Peruvians participants remained constant in some of the key variables under study. Among those who changed, the change was often towards healthier eating habits, with an increase in the frequency of consumption of vegetables, fruit, legumes, eggs, and a decrease in bakery products. More than $70 \%$ of the participants reported changes in their sleep pattern, and more than half indicated an increase in physical activity despite the social isolation. However, perception of weight gain was also reported.

This study highlights the potential impact of social isolation due to COVID-19 by including a variety of weightrelated behaviors in Peruvian adults. The results of this study indicate that of all the participants subjected to social 
TABLE 2: Lifestyles during social isolation.

\begin{tabular}{|c|c|c|c|c|}
\hline Variables & Total $(n=1176)$ & Men $(n=571)$ & Women $(n=605)$ & $p$ value \\
\hline \multicolumn{5}{|l|}{ Physical activity (PA) } \\
\hline No & $532(45.2)$ & $258(45.2)$ & $274(45.3)$ & \multirow[t]{2}{*}{1} \\
\hline Yes & $644(54.8)$ & $313(54.8)$ & $331(54.7)$ & \\
\hline \multicolumn{5}{|l|}{ Days per week } \\
\hline None & $532(45.2)$ & $258(45.2)$ & $274(45.3)$ & \multirow[t]{5}{*}{0.204} \\
\hline 1 to 2 days & $173(14.7)$ & $76(13.3)$ & $97(16.0)$ & \\
\hline 3 to 4 days & $310(26.4)$ & $147(25.7)$ & $163(26.9)$ & \\
\hline 5 to 6 days & $131(11.1)$ & $71(12.4)$ & $60(9.9)$ & \\
\hline 7 days & $30(2.6)$ & $19(3.3)$ & $11(1.8)$ & \\
\hline \multicolumn{5}{|l|}{ Duration } \\
\hline No physical activity & $532(45.2)$ & $258(45.2)$ & $274(45.3)$ & \multirow[t]{5}{*}{0.425} \\
\hline Less than 30 minutes & $257(21.9)$ & $122(21.4)$ & $135(22.3)$ & \\
\hline 30 minutes to 1 hour & $335(28.5)$ & $159(27.8)$ & $176(29.1)$ & \\
\hline 1 to 2 hours & $46(3.9)$ & $28(4.9)$ & $18(3.0)$ & \\
\hline Other & $6(0.5)$ & $4(0.7)$ & $2(0.3)$ & \\
\hline \multicolumn{5}{|l|}{ Sleep routine } \\
\hline No change & $304(25.9)$ & $171(29.9)$ & $133(22.0)$ & \multirow[t]{3}{*}{$0.006^{*}$} \\
\hline Sleep more & $434(36.9)$ & $204(35.7)$ & $230(38.0)$ & \\
\hline Sleep less & $438(37.2)$ & $196(34.3)$ & $242(40.0)$ & \\
\hline \multicolumn{5}{|l|}{ Hours of sleep } \\
\hline 0 to 3 hours & $25(2.1)$ & $12(2.1)$ & $13(2.1)$ & \multirow[t]{4}{*}{0.170} \\
\hline 4 to 6 hours & $419(35.6)$ & $188(32.9)$ & $231(38.2)$ & \\
\hline 7 to 9 hours & $651(55.4)$ & $335(58.7)$ & $316(52.2)$ & \\
\hline$>10$ hours & $81(6.9)$ & $36(6.3)$ & $45(7.4)$ & \\
\hline
\end{tabular}

Data expressed as absolute and relative frequency (\%). *Statistically significant, $p<0.05$.

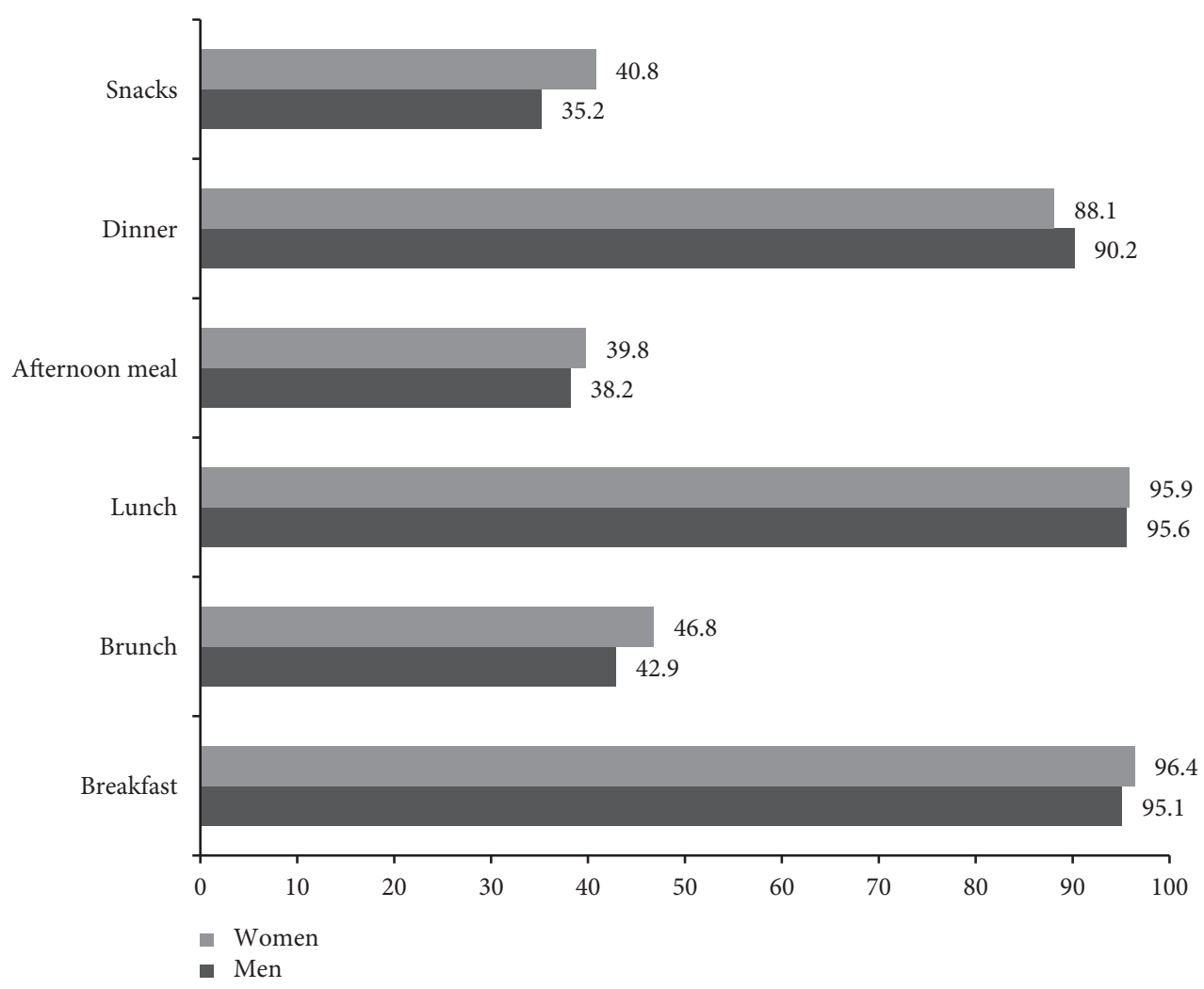

FIGURE 1: Frequency of eating patterns during social isolation. 
TABLE 3: Changes in consumption of food before and during social isolation.

\begin{tabular}{|c|c|c|c|c|c|}
\hline Type of food & Low $^{\mathrm{a}}$ & High $^{a}$ & OR & (CI95\%) & $p$ value \\
\hline \multicolumn{6}{|l|}{ Vegetables } \\
\hline Before & $628(53.4)$ & $548(46.6)$ & 1 & (Reference) & \multirow[t]{2}{*}{$<0.01$} \\
\hline During & $569(48.4)$ & $607(51.6)$ & 1.56 & $(1.21-2.00)$ & \\
\hline \multicolumn{6}{|l|}{ Fruit } \\
\hline Before & $627(53.3)$ & $549(46.7)$ & 1 & (Reference) & \multirow[t]{2}{*}{$<0.01$} \\
\hline During & $579(49.2)$ & $597(50.8)$ & 1.42 & $(1.10-1.81)$ & \\
\hline \multicolumn{6}{|l|}{ Legumes } \\
\hline Before & $927(78.8)$ & $249(21.2)$ & 1 & (Reference) & \multirow[t]{2}{*}{$<0.01$} \\
\hline During & $881(74.9)$ & $295(25.1)$ & 1.67 & $(1.23-2.28)$ & \\
\hline \multicolumn{6}{|l|}{ Eggs } \\
\hline Before & $887(75.4)$ & $289(24.6)$ & 1 & (Reference) & \multirow[t]{2}{*}{$<0.01$} \\
\hline During & $808(68.7)$ & $368(31.3)$ & 2.00 & $(1.52-2.65)$ & \\
\hline \multicolumn{6}{|c|}{ Bakery products } \\
\hline Before & $699(59.4)$ & $477(40.6)$ & 1 & (Reference) & \multirow[t]{2}{*}{$<0.05$} \\
\hline During & $733(62.3)$ & $443(37.7)$ & 0.74 & $(0.56-0.97)$ & \\
\hline
\end{tabular}

Data expressed as absolute and relative frequency (\%). OR: odds ratios; CI95\%, confidence interval 95\%. ${ }^{\mathrm{a}}$ Consumption of food.

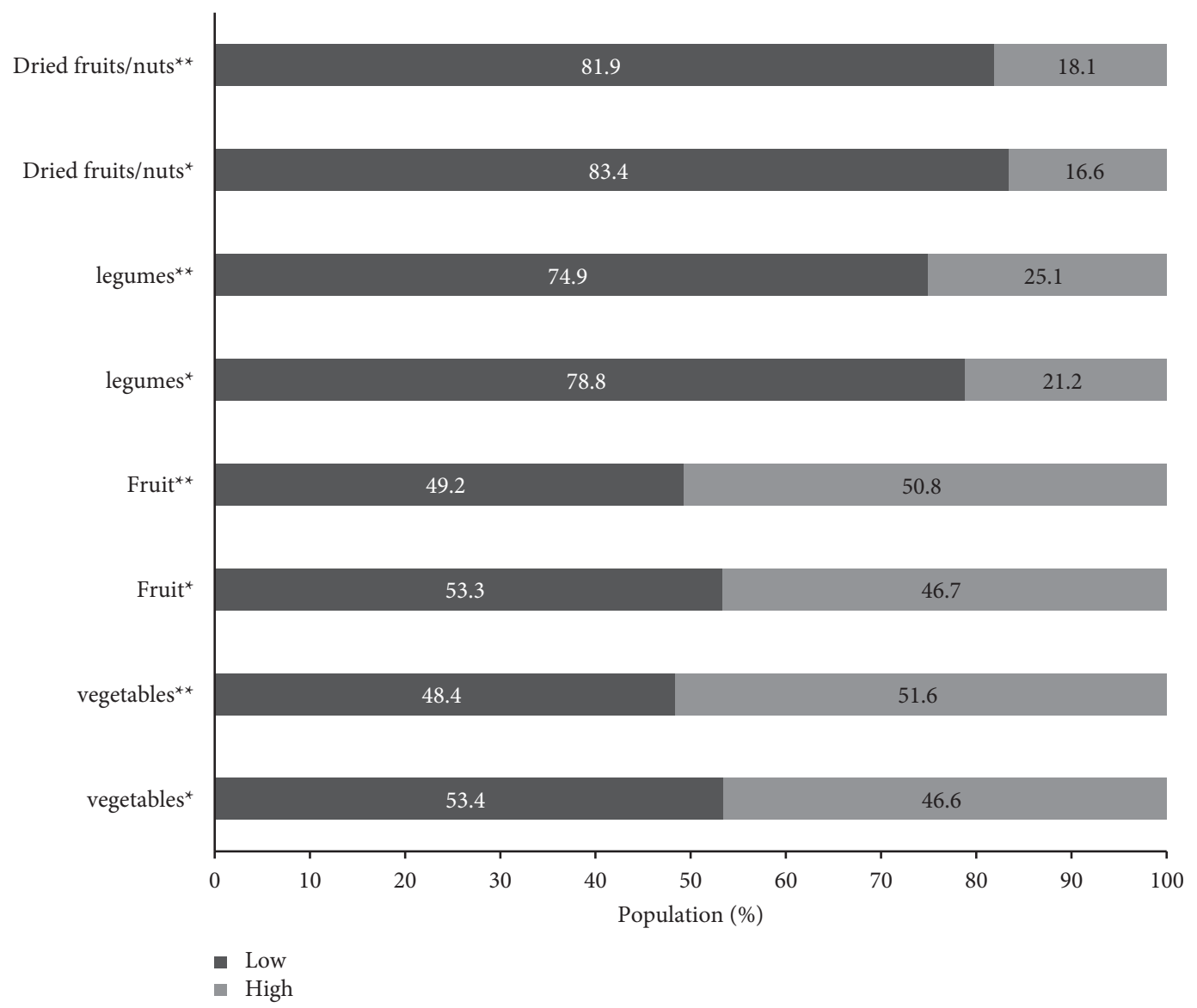

Figure 2: Changes in the frequency of low and high consumption of plant-based foods before and during social isolation. *Before social isolation; ${ }^{* *}$ during social isolation.

isolation measures, $35.7 \%$ and $8.4 \%$ were overweight and obese, respectively. In addition, it is also evidenced that half of the participants gained weight. Likewise, the findings show that the imposition of social isolation influenced lifestyles causing negative effects and weight changes, as the participants reported gaining weight with $20.8 \%$ between 1 and $3 \mathrm{~kg}$ and $13.7 \%$ from 4 to $7 \mathrm{~kg}$, respectively. Similar studies in Ibero-American countries indicated a weight gain in $48.6 \%$ of participants during social isolation [20]. Moreover, a study with 639 Chilean participants indicated an average weight gain of $1.99 \mathrm{~kg}$ [21]. These similar results may be because the population of this region of the world has similar eating habits, as was demonstrated in a representative sample of the urban population of Latin America [22]. 


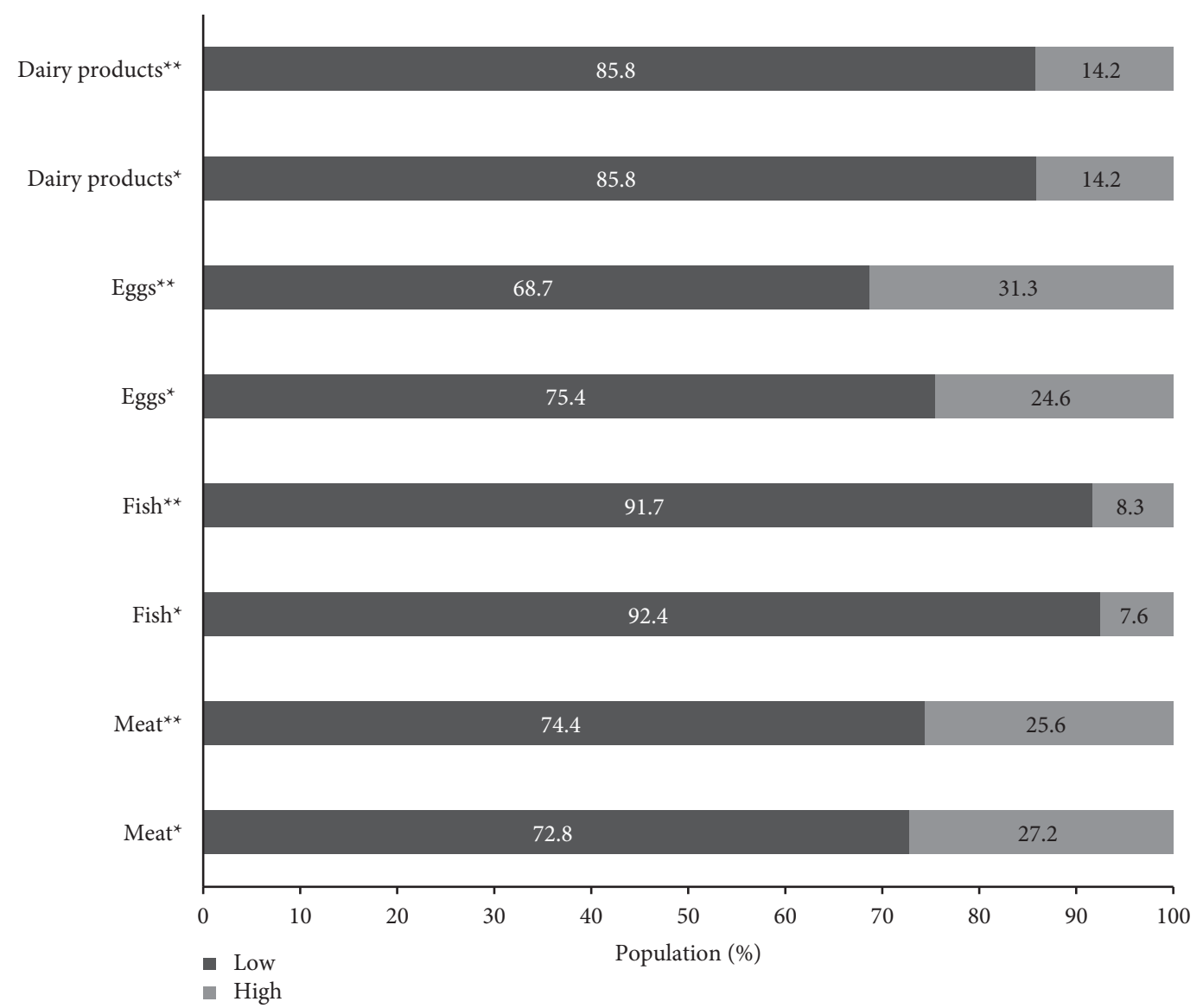

FIGURE 3: Changes in the frequency of low and high consumption of animal-based foods before and during social isolation. * Before social isolation; ${ }^{* *}$ during social isolation.

On the other hand, studies in different Latin American countries such as Argentina, Mexico, and Brazil showed high proportions of their population with overweight and obesity during the period of social isolation [20]. Additionally, in another study with Chilean adults, an increase of 0.7 units of BMI was reported [21]. The population of these countries presented a low overall diet quality score and low dietary diversity [23]. Additionally, during the first mandatory isolation, in Peru as in these countries with high prevalence of obesity, low levels of physical activity were reported [24]. These factors could be influencing the increase of BMI.

Although energy intake and energy expenditure were not measured, it is possible that there is a possible imbalance between them, which could be contributing to weight gain, regardless of the quality of the diet. Higher daily energy intakes were reported during social isolation periods due to the pandemic [25], and other factors that could contribute to the weight gain perceived by the participants could be alterations in their sleep pattern [26] and high rates of stress and depression that lead people to consume foods with high sugar content, irregularity of the meals, with a greater consumption of food outside the main meals (snacks and intermediate meals in the morning and afternoon) [27].

It is recommended to adopt and maintain healthy lifestyle habits as a fundamental principle of physical health, especially during confinement due to COVID-19. Prepandemic studies showed that the Peruvian population had a high prevalence of physical inactivity and sedentary behaviors [28]. This study found changes in behavior during social isolation; the majority of participants claimed to be physically active (54.8\%) for 1-2 (14.7\%) or 3-4 (26.4\%) days per week, for at least 30 minutes. Similar studies showed increased reporting of moderate and vigorous physical activity in older adults during social isolation [29]. On the other hand, other studies show that total physical activity decreased significantly during social isolation, due to greater sedentary behavior, more prolonged during the weekend, increase in sitting time, or only low-intensity activities such as housework [30].

This sudden cessation of physical exercise is detrimental in the context of this disease, since this decrease is associated with rapid muscle atrophy and reduced energy consumption by the muscles, promoting obesity and lipid accumulation, decreased ability of organ systems to resist viral infection, and increased risk of damage to the immune system, respiratory system, cardiovascular system, musculoskeletal system, and brain [31]. Additionally, in this study, the physical activity at home, at least 30 minutes per day and more days of practice per week, significantly reduced the probability of high BMI. That is why the WHO recommends at least 150 minutes per week of moderate to vigorous 


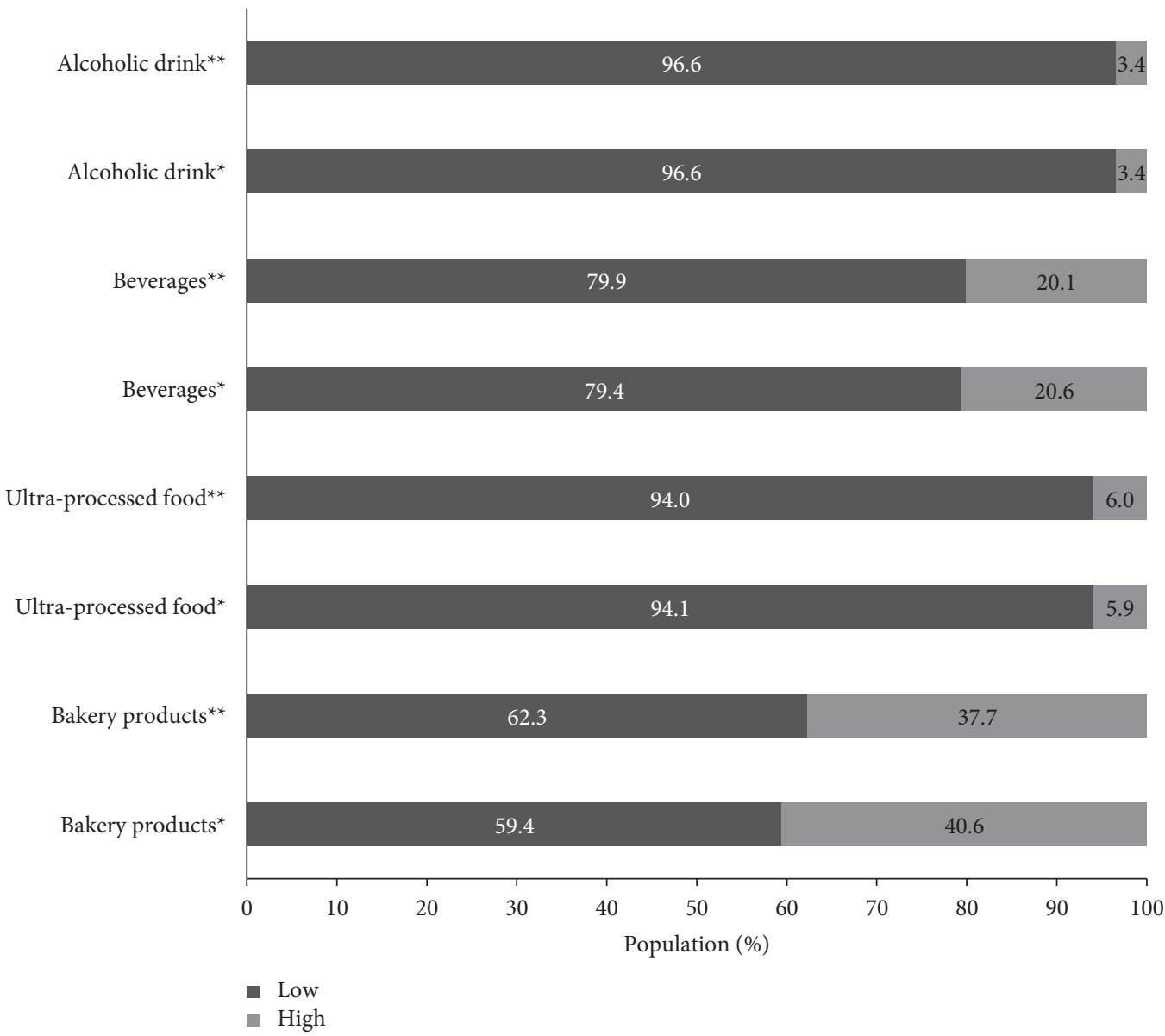

FIgURE 4: Changes in the frequency of low and high consumption of processed food before and during social isolation. * Before social isolation; ${ }^{* *}$ during social isolation.

TAвLE 4: Factors associated with high body mass index during the COVID-19 pandemic in the study sample.

\begin{tabular}{|c|c|c|c|c|}
\hline \multirow{2}{*}{ Variables } & \multicolumn{2}{|c|}{ BMI } & \multirow{2}{*}{ ORc (CI95\%) } & \multirow{2}{*}{ ORa (CI95\%) } \\
\hline & $<25 \mathrm{~kg} / \mathrm{m}^{2}(n=657)$ & $\geq 25 \mathrm{~kg} / \mathrm{m}^{2}(n=519)$ & & \\
\hline Age (years) & $28.0 \pm 11.0$ & $35.1 \pm 12.4$ & $1.05(1.04-1.06)^{* *}$ & - \\
\hline \multicolumn{5}{|l|}{ Sex $(\%)$} \\
\hline Men & $250(43.8)$ & $321(56.2)$ & 1 & - \\
\hline Women & $407(67.3)$ & $198(32.7)$ & $0.38(0.30-0.48)^{* *}$ & - \\
\hline \multicolumn{5}{|l|}{ Vegetables (\%) } \\
\hline No & $299(52.5)$ & $270(47.5)$ & 1 & 1 \\
\hline Yes & $358(59.0)$ & $249(41.0)$ & $0.77(0.61-0.97)^{*}$ & $0.87(0.68-1.11)$ \\
\hline \multicolumn{5}{|l|}{$\mathrm{PA}$ at home (\%) } \\
\hline No & $255(47.9)$ & $277(52.1)$ & 1 & 1 \\
\hline Yes & $402(62.4)$ & $242(37.6)$ & $0.55(0.44-0.70)^{* *}$ & $0.58(0.45-0.74)^{* *}$ \\
\hline PA per week (days) & $2.1 \pm 2.1$ & $1.6 \pm 2.0$ & $0.89(0.84-0.94)^{* *}$ & $0.89(0.84-0.94)^{* * *}$ \\
\hline \multicolumn{5}{|l|}{ Time of PA (\%) } \\
\hline No physical activity & $255(47.9)$ & $277(52.1)$ & 1 & 1 \\
\hline Less than 30 minutes & $156(60.7)$ & $101(39.3)$ & $0.60(0.44-0.81)^{* *}$ & $0.61(0.44-0.84)^{* *}$ \\
\hline 30 minutes to 1 hour & $217(64.8)$ & $118(35.2)$ & $0.50(0.38-0.66)^{* *}$ & $0.54(0.40-0.73)^{* *}$ \\
\hline 1 to 2 hours & $27(58.7)$ & $19(41.3)$ & $0.65(0.35-1.19)$ & $0.64(0.33-1.21)$ \\
\hline Others & $2(33.3)$ & $4(66.7)$ & $1.84(0.36-13.36)$ & $1.01(0.18-8.03)$ \\
\hline
\end{tabular}

Data expressed as absolute and relative frequency (\%) or mean \pm SD. cOR, crude odds ratios; aOR, adjusted odds ratio by all sex and age; CI95\%, confidence interval 95\%; PA, physical activity. ${ }^{* *} P<0.01$. 
TABLE 5: Factors associated with sleep changes during the COVID-19 pandemic in the study sample.

\begin{tabular}{|c|c|c|c|c|}
\hline \multirow{2}{*}{ Variables } & \multicolumn{2}{|c|}{ Sleep changes } & \multirow{2}{*}{ ORc (IC95\%) } & \multirow{2}{*}{ ORa (IC95\%) } \\
\hline & No $(n=304)$ & Yes $(n=872)$ & & \\
\hline Age (years) & $33.5 \pm 12.9$ & $30.3 \pm 11.8$ & $0.98(0.97-0.99)^{* *}$ & - \\
\hline \multicolumn{5}{|l|}{$\operatorname{Sex}(\%)$} \\
\hline Men & $171(29.9)$ & $400(70.1)$ & 1 & - \\
\hline Women & $133(22.0)$ & $472(78.0)$ & $1.52(1.17-1.98)^{* *}$ & - \\
\hline \multicolumn{5}{|l|}{ Social isolation (\%) } \\
\hline Have not been socially isolated & $54(37.8)$ & $89(62.2)$ & 1 & 1 \\
\hline Less than 15 days & $15(40.5)$ & $22(59.5)$ & $0.89(0.43-1.89)$ & $0.84(0.40-1.79)$ \\
\hline 15 to 30 days & $17(28.8)$ & $42(71.2)$ & $1.50(0.79-2.95)$ & $1.65(0.86-3.26)$ \\
\hline 31 to 45 days & $19(46.3)$ & $22(53.7)$ & $0.70(0.35-1.42)$ & $0.78(0.38-1.59)$ \\
\hline 45 to 60 days & $33(32.7)$ & $68(67.3)$ & $1.25(0.73-2.15)$ & $1.35(0.79-2.34)$ \\
\hline More than 61 days & $166(20.9)$ & $629(79.1)$ & $2.30(1.57-3.35)^{* *}$ & $2.31(1.57-3.38)^{* *}$ \\
\hline Meals per day & $3.8 \pm 1.1$ & $4.1 \pm 1.2$ & $1.21(1.08-1.35)^{* *}$ & $1.17(1.05-1.32)^{* *}$ \\
\hline
\end{tabular}

Data expressed as absolute and relative frequency (\%) or mean \pm SD. cOR, crude odds ratios; aOR, adjusted odds ratio by all sex and age; CI95\%, confidence interval $95 \% ;{ }^{* *} P<0.01$.

intensity physical activity or 75 minutes of high-intensity physical activity per week or a combination of both [32].

Sleep plays a critical role in physical and mental health, and adequate sleep duration and quality are essential to cope with major life events such as the COVID-19 pandemic [33]. More than $70 \%$ of the participants in this study reported substantial changes in their sleep patterns during the period of isolation due to COVID-19. Similar studies revealed a high prevalence of anxiety sleep disorders and depressive symptoms in the population during the COVID-19 social isolation period, with women reporting a higher risk of sleep difficulties [34], which was also observed in our study. It is likely that women were more receptive to expressing psychological distress and somatic symptoms [35]. When the factors associated with alterations in sleep habits were analyzed, it was determined that the social isolation for more than 61 days increased the probability of sleep changes by 2.31 times. On the other hand, the uncertainty of being infected by the coronavirus would cause greater pressure in the population, relating to hypochondriacal concerns, sleep apnea, and childhood trauma that can be reflected in sleep mentality, affecting its quality [36]. Most of the participants in this study were students and workers under the age of 40 , who probably had to change their activities from in-person to online, and these changes in their routines could have influenced and altered the physiological regulators of sleep.

This study also showed significant changes in the eating habits that this Peruvian population adopted during social isolation, among which the increase of eggs, legumes, fruit, and vegetables, as well as the decrease of bakery products. Some studies observed an improvement in the pattern of consumption of healthy foods and a restriction of unhealthy foods, especially in the younger population ( $<30$ years) [37]. In contrast, studies in Italy indicated changes in eating habits in almost half the population so that women were more likely than men to increase their food intake to feel better [9]. In other countries, after-dinner snacks, carbohydrate consumption, consumption of sweets, cookies, and cakes and consumption of fresh food products increased [26]. The lack of dietary and eating restriction may be due to a response to stress and reduced physical activity, which could lead to decreased nutritional quality [26]. Additionally, the addition of each extra meal during the day increased the probability of sleep changes by $17 \%$. This unhealthy behavior is observed in other studies, primarily in adult populations with obesity and in settings with a lower eating environment index [38].

Prepandemic studies carried out in the Latin American population, including Peru, revealed low dietary diversity and low frequency of consumption of food groups rich in micronutrients, so they deserve a lot of attention and care [23]. Although the Peruvian population had the highest consumption of fruit and whole grains and the lowest consumption of red and processed meats compared to other Latin American countries, they had the highest consumption of homemade sugar-sweetened beverages [22]. In our study, 80\% of the participants indicated consuming this type of beverages.

In addition to changes in eating habits, alcoholic drinks and ultra-processed food consumption was the lowest and showed no changes before and during social isolation. Some studies suggest that increased alcohol consumption during the COVID-19 pandemic may be a response to boredom, inactivity, isolation, and as a means of combating anxiety, stress, and/or loss of sleep as a result of containment measures introduced to minimize the spread of the virus [39].

Changes towards a better quality of eating habits are necessary for the Peruvian population, especially in the context of the COVID-19 pandemic, where Peru is the country with the most deaths per capita [40]. Recent studies show that a varied plant-based diet improves the immune response, can exert anti-inflammatory, antioxidant, cytoprotective, and even antiviral properties [41]. Additionally, the fibers found abundantly in fruit and vegetables improve the intestinal microbiota and provide protective phytochemicals [42]. Promoting the consumption of a healthy diet represents an important challenge for this country and could potentially prevent the future appearance of chronic diseases.

The main limitation of this study is the lack of representativeness of the population sample. Therefore, it is not possible to expand the results to the population of the whole country. There is also an overrepresentation of younger 
individuals $(<25$ years). Moreover, all data collected are selfreported, and this could make them not completely reliable, especially when it comes to reporting behaviors for which there may be a social stigma (e.g., alcohol). Another limitation could be the lack of information about religious practices, which could have influenced diet and lifestyle changes, as well as the lack of questions about whole food consumption. The findings are also limited by the absence of data on smoking and comorbidities, important factors affecting many lifestyles.

\section{Conclusion}

In conclusion, the findings of this study carried out in a Peruvian population during the COVID-19 pandemic demonstrated an increase in the practices of healthy eating habits, including a higher consumption of fruit, vegetables, legumes, and eggs and a lower intake of bakery products and ultra-processed foods. Also, more than $70 \%$ of the participants reported changes in their sleep pattern, where those who had been in social isolation for more than 61 days were 2.31 times as likely to experience sleep changes. Additionally, more than half indicated an increase in physical activity despite social isolation, where physical activity at home for at least 30 minutes per day and more days of practice per week significantly reduced the probability of high BMI. However, this study also showed that half of the participants reported weight gain. Future studies should consider additional potential factors, starting with the observation in this study that most participants had a changed sleep pattern during social isolation and potentially including other factors like stress, type of exercise, pedometer step counts, and portion sizes.

\section{Data Availability}

The data presented in this study are available on request from the corresponding author.

\section{Disclosure}

A preprint has previously been published in "medRxiv" [43].

\section{Conflicts of Interest}

The authors declare that they have no conflicts of interest.

\section{Authors' Contributions}

S.H-V., E.E.N-N., and R.R-H. have contributed to conceptualization, formal analysis, and writing of the manuscript. J.S., M.R.V., and P.G.R-M. helped in data curation and writing and original draft preparation. W.C.M-G. and M.W. contributed to the investigation and manuscript writing. All authors have read and agreed to the published version of the manuscript.

\section{References}

[1] T. P. Velavan and C. G. Meyer, "The COVID-19 epidemic," Tropical Medicine and International Health, vol. 25, no. 3, pp. 278-280, 2020.

[2] COVID-19 Map, Johns Hopkins Coronavirus Resource Center, 2021, https://coronavirus.jhu.edu/map.html.
[3] L. Di Renzo, P. Gualtieri, F. Pivari et al., "Eating habits and lifestyle changes during COVID-19 lockdown: an Italian survey," Journal of Translational Medicine, vol. 18, no. 1, p. $229,2020$.

[4] P. Heuveline and M. Tzen, "Beyond deaths per capita: comparative COVID-19 mortality indicators," BMJ Open, vol. 11, no. 3, Article ID e042934, 2021.

[5] Gobierno del Perú, Decreto Supremo N 008-2020-SA que declara en emergencia sanitaria a nivel nacional por el plazo de noventa (90) días calendario y dicta medidas prevención y control del Covid-19, Diario Oficial El Peruano, 11 de marzo de 2020.

[6] Gobierno del Perú, Decreto Supremo N 009-2021-SA que declara en emergencia sanitaria a nivel nacional por el plazo de ciento ochenta (180) días calendarios y dicta medidas prevención y control del Covid-19, Diario Oficial El Peruano, 19 de febrero de 2021.

[7] M. Pellegrini, V. Ponzo, R. Rosato et al., "Changes in weight and nutritional habits in adults with obesity during the "lockdown" period caused by the COVID-19 virus emergency," Nutrients, vol. 12, no. 7, 2020.

[8] H. Najera, S. Nandy, R. M. Carrillo-Larco, and J. J. Miranda, "Within-country migration and obesity dynamics: analysis of 94,783 women from the Peruvian demographic and health surveys," BMC Public Health, vol. 19, no. 1, p. 263, 2019.

[9] L. Di Renzo, P. Gualtieri, G. Cinelli et al., "Psychological aspects and eating habits during COVID-19 home confinement: results of EHLC-COVID-19 Italian online survey," Nutrients, vol. 12, no. 7, 2020.

[10] J.-P. Chaput and C. Dutil, "Lack of sleep as a contributor to obesity in adolescents: impacts on eating and activity behaviors," International Journal of Behavioral Nutrition and Physical Activity, vol. 13, no. 1, p. 103, 2016.

[11] V. Garfield, C. H. Llewellyn, and M. Kumari, "The relationship between physical activity, sleep duration and depressive symptoms in older adults: the English Longitudinal Study of Ageing (ELSA)," Preventive medicine reports, vol. 4, pp. 512-516, 2016.

[12] Q. Feng, Q. L. Zhang, Y. Du, Y. L. Ye, and Q. Q. He, “Associations of physical activity, screen time with depression, anxiety and sleep quality among Chinese college freshmen," PLoS One, vol. 9, no. 6, Article ID e100914, 2014.

[13] D. Reyes-Olavarría, P. Latorre-Román, I. P. GuzmánGuzmán, D. Jerez-Mayorga, F. Caamaño-Navarrete, and P. Delgado-Floody, "Positive and negative changes in food habits, physical activity patterns, and weight status during COVID-19 confinement: associated factors in the Chilean population," International Journal of Environmental Research and Public Health, vol. 17, no. 15, 2020.

[14] C. Wang, R. Pan, X. Wan et al., "Immediate psychological responses and associated factors during the initial stage of the 2019 coronavirus disease (COVID-19) epidemic among the general population in China," International Journal of Environmental Research and Public Health, vol. 17, no. 5, 2020.

[15] C. Evers, A. Dingemans, A. F. Junghans, and A. Boevé, "Feeling bad or feeling good, does emotion affect your consumption of food? A meta-analysis of the experimental evidence," Neuroscience \& Biobehavioral Reviews, vol. 92, pp. 195-208, 2018.

[16] M. J. Butler and R. M. Barrientos, "The impact of nutrition on COVID-19 susceptibility and long-term consequences," Brain, Behavior, and Immunity, vol. 87, pp. 53-54, 2020.

[17] Y. Dun, J. W. Ripley-Gonzalez, N. Zhou et al., "Weight gain in Chinese youth during a 4-month COVID-19 lockdown: a 
retrospective observational study," BMJ Open, vol. 11, no. 7, Article ID e052451, 2021.

[18] E. T. van der Werf, M. Busch, M. C. Jong, and H. J. R. Hoenders, "Lifestyle changes during the first wave of the COVID-19 pandemic: a cross-sectional survey in The Netherlands," BMC Public Health, vol. 21, no. 1, p. 1226, 2021.

[19] I. Lazarevich, M. E. Irigoyen Camacho, M. C. Velázquez-Alva, N. L. Flores, O. Nájera Medina, and M. A. Zepeda Zepeda, "Depression and food consumption in Mexican college students," Nutricion Hospitalaria, vol. 35, no. 3, pp. 620-626, 2018.

[20] O. G. Enriquez-Martinez, M. C. T. Martins, T. S. S. Pereira et al., "Diet and lifestyle changes during the COVID-19 pandemic in Ibero-American countries: Argentina, Brazil, Mexico, Peru, and Spain," Frontiers in Nutrition, vol. 8, p. $671004,2021$.

[21] A. R. Navarro-Cruz, A. Kammar-García, J. Mancilla-Galindo et al., "Association of differences in dietary behaviours and lifestyle with self-reported weight gain during the COVID-19 lockdown in a university community from Chile: a crosssectional study," Nutrients, vol. 13, no. 9, 2021.

[22] I. Kovalskys, A. Rigotti, B. Koletzko et al., "Latin American consumption of major food groups: results from the ELANS study," PLoS One, vol. 14, no. 12, Article ID e0225101, 2019.

[23] G. Gómez, R. M. Fisberg, Á. Nogueira Previdelli et al., "Diet quality and diet diversity in eight Latin American countries: results from the Latin American study of nutrition and health (ELANS)," Nutrients, vol. 11, no. 7, 2019.

[24] R. Jayawardena, D. T. Jeyakumar, A. Misra, A. P. Hills, and P. Ranasinghe, "Obesity: a potential risk factor for infection and mortality in the current COVID-19 epidemic," Diabetes \& Metabolic Syndrome: Clinical Research Reviews, vol. 14, no. 6, pp. 2199-2203, 2020.

[25] L. A. Gallo, T. F. Gallo, S. L. Young, K. M. Moritz, and L. K. Akison, "The impact of isolation measures due to COVID-19 on energy intake and physical activity levels in Australian university students," Nutrients, vol. 12, no. 6, 2020.

[26] Z. Zachary, F. Brianna, L. Brianna et al., "Self-quarantine and weight gain related risk factors during the COVID-19 pandemic," Obesity Research \& Clinical Practice, vol. 14, no. 3, pp. 210-216, 2020.

[27] H. Znazen, M. Slimani, N. L. Bragazzi, and D. Tod, "The relationship between cognitive function, lifestyle behaviours and perception of stress during the COVID-19 induced confinement: insights from correlational and mediation analyses," International Journal of Environmental Research and Public Health, vol. 18, no. 6, 2021.

[28] G. L. d. M. Ferrari, I. Kovalskys, M. Fisberg et al., "Sociodemographic patterning of objectively measured physical activity and sedentary behaviours in eight Latin American countries: findings from the ELANS study," European Journal of Sport Science, vol. 20, no. 5, pp. 670-681, 2020.

[29] A. Carriedo, J. A. Cecchini, J. Fernández-Río, and A. MéndezGiménez, "Resilience and physical activity in people under home isolation due to COVID-19: a preliminary evaluation," Mental Health and Physical Activity, vol. 19, Article ID 100361, 2020.

[30] G. Maugeri, P. Castrogiovanni, G. Battaglia et al., "The impact of physical activity on psychological health during Covid-19 pandemic in Italy," Heliyon, vol. 6, no. 6, Article ID e04315, 2020.

[31] J. Woods, N. T. Hutchinson, S. K. Powers, W. O. Roberts, M. C. Gomez-Cabrera, and Z. Radak, "The COVID-19 pandemic and physical activity," Sports Medicine and Health Science, vol. 2, no. 2, pp. 55-64, 2020.

[32] D. K. Arnett, R. S. Blumenthal, M. A. Albert, A. B. Buroker, Z. D. Goldberger, and E. J. Hahn, "ACC/AHA guideline on the primary prevention of cardiovascular disease: a report of the American college of cardiology/American heart association task force on clinical practice guidelines," Journal of the American College of Cardiology, vol. 74, no. 10, pp. e177-e232, 2019.

[33] C. M. Morin, J. Carrier, C. Bastien, and R. Godbout, "Sleep and circadian rhythm in response to the COVID-19 pandemic," Canadian Journal of Public Health, vol. 111, no. 5, pp. 654-657, 2020.

[34] J. Pinto, M. van Zeller, P. Amorim et al., "Sleep quality in times of Covid-19 pandemic," Sleep Medicine, vol. 74, pp. 81-85, 2020.

[35] H. Jahrami, A. S. BaHammam, H. AlGahtani et al., "The examination of sleep quality for frontline healthcare workers during the outbreak of COVID-19," Sleep \& breathing = Schlaf \& Atmung, vol. 25, no. 1, pp. 503-511, 2020.

[36] Y. Huang and N. Zhao, "Generalized anxiety disorder, depressive symptoms and sleep quality during COVID-19 outbreak in China: a web-based cross-sectional survey," Psychiatry Research, vol. 288, Article ID 112954, 2020.

[37] S. Chopra, P. Ranjan, V. Singh et al., "Impact of COVID-19 on lifestyle-related behaviours- a cross-sectional audit of responses from nine hundred and ninety-five participants from India," Diabetes \& Metabolic Syndrome: Clinical Research Reviews, vol. 14, no. 6, pp. 2021-2030, 2020.

[38] E. Robinson, E. Boyland, A. Chisholm et al., "Obesity, eating behavior and physical activity during COVID-19 lockdown: a study of UK adults," Appetite, vol. 156, Article ID 104853, 2021.

[39] A. F. Yan, X. Sun, J. Zheng et al., "Perceived risk, behavior changes and Health-related outcomes during COVID-19 pandemic: findings among adults with and without diabetes in China," Diabetes Research and Clinical Practice, vol. 167, Article ID 108350, 2020.

[40] A. Schwalb and C. Seas, "The COVID-19 pandemic in Peru: what went wrong?" The American Journal of Tropical Medicine and Hygiene, vol. 104, no. 4, pp. 1176-1178, 2021.

[41] S. A. Llivisaca-Contreras, J. Naranjo-Morán, A. Pino-Acosta et al., "Plants and natural products with activity against various types of coronaviruses: a review with focus on SARSCoV-2," Molecules, vol. 26, no. 13, 2021.

[42] C. Ferreira, S. D. Viana, and F. Reis, "Is gut microbiota dysbiosis a predictor of increased susceptibility to poor outcome of COVID-19 patients? An update," Microorganisms, vol. 9, no. 1, 2020.

[43] S. Huancahuire-Vega, E. E. Newball-Noriega, R. RojasHumpire et al., "Changes in eating habits and lifestyles in Peruvian population during social isolation by the COVID-19 pandemic," medRxiv, p. 2021, 2021. 